\title{
Glucose concentration during equine in vitro maturation alters mitochondrial function
}

\author{
Niamh Lewis ${ }^{1}$, Katrin Hinrichs ${ }^{2,}{ }^{*}$, Henry J Leese 3 , Caroline McGregor Argo ${ }^{1,+}$, \\ Daniel R Brison ${ }^{4,5}$ and Roger G Sturmey ${ }^{3,5}$ \\ ${ }^{1}$ Institute of Ageing and Chronic Disease, University of Liverpool, Cheshire, UK, ${ }^{2}$ Department of Veterinary \\ Physiology and Pharmacology, Texas A\&M University, College Station, Texas, USA, ${ }^{3}$ Centre for Atherothrombosis \\ and Metabolic Disease, Hull York Medical School, University of Hull, Hull, UK, ${ }^{4}$ Maternal and Fetal Health \\ Research, Faculty of Biology, Medicine \& Health, University of Manchester, Manchester Academic Health Science \\ Centre, Manchester, UK and ${ }^{5}$ Department of Reproductive Medicine, St Mary's Hospital, Manchester NHS \\ Foundation Trust, Manchester Academic Health Science Centre, Manchester, UK
}

Correspondence should be addressed to N Lewis; Email: n.lewis@liverpool.ac.uk

*(K Hinrichs is now at Department of Clinical Studies-New Bolton Center, School of Veterinary Medicine, University of Pennsylvania, PA, USA)

${ }^{\dagger}$ (C McGregor Argo is now at Scotland's Rural College (SRUC), Northern Faculty, Craibstone Campus, Aberdeen, Scotland)

\begin{abstract}
The use of in vitro embryo production in the horse is increasing in clinical and research settings; however, protocols are yet to be optimised. Notably, the two most commonly used base media for in vitro maturation (IVM) supply glucose at markedly different concentrations: physiological (5.6 mM, M199) or supraphysiological (17 mM, DMEM/F-12). Exposure to high glucose has detrimental effects on oocytes and early embryos in many mammalian species, but the impact has not yet been examined in the horse. To address this, we compared the energy metabolism of equine COCs matured in M199-based maturation medium containing either 5.6 or 17 $\mathrm{mM}$ glucose, as well as expression of key genes in oocytes and cumulus cells. Oocytes were fertilised by ICSI and cultured. Analysis of spent medium revealed that $\mathrm{COC}$ glucose consumption and production of lactate and pyruvate were similar between treatments. However, the glycolytic index was decreased at $17 \mathrm{mM}$ and analysis of mitochondrial function of COCs revealed that IVM in $17 \mathrm{mM}$ glucose was associated with decreased ATP-coupled respiration and increased non-mitochondrial respiration compared to that for 5.6 $\mathrm{mM}$ glucose. We also found that the metabolic enzyme lactate dehydrogenase-A ( $L D H A)$ was downregulated in cumulus cells of oocytes that completed IVM in $17 \mathrm{mM}$ glucose. There was no difference in maturation or blastocyst rates. These data indicate that COC mitochondrial function and gene expression are altered by high glucose concentration during IVM. Further work is needed to determine if these changes are associated with developmental changes in the resulting offspring.

Reproduction (2020) $160227-237$
\end{abstract}

\section{Introduction}

In vitro equine embryo production following intracytoplasmic sperm injection (ICSI) and in vitro embryo culture is currently used worldwide, both for research and clinical production of foals (Galli et al. 2007, Hinrichs et al. 2010, Claes et al. 2019). Superovulation remains problematic in the horse (Roser \& Meyers-Brown 2012), meaning that recovery of immature oocytes followed by in vitro oocyte maturation $(I V M)$ is typically used to maximise the number of mature oocytes available for fertilisation. The most widely used media for equine IVM are M199 (Zhang et al. 1989) and DMEM/F-12, (Galli et al. 2007). When compared directly, DMEM/F12 was superior to M199-based IVM medium in terms of subsequent blastocyst development in one study (26.4\% for DMEM/F12 vs $12 \%$ for M199; Galli et al. 2007). However, M199-based IVM has been reported by other laboratories to support high rates of blastocyst production (up to 54\%; Hinrichs et al. 2005, Jacobson et al. 2010, Salgado et al. 2018, Brom-de-Luna et al. 2019).

A major difference between these two systems for equine IVM is the concentration at which glucose is supplied. M199 contains $5.6 \mathrm{mM}$ of glucose, which is close to the concentration found in the equine ovarian follicle (3.15-5.01 mmol/L of glucose; Collins et al. 1997), whereas DMEM/F12 provides glucose at 17 $\mathrm{mM}$. In other mammalian species such as the mouse and cow, such high glucose concentrations during oocyte maturation have been associated with delayed meiotic kinetics, increased apoptosis, decreased oocyte 
ATP content, disrupted glucose metabolism, changes in mitochondrial distribution and morphology, and compromised oocyte-cumulus cell communication (Colton et al. 2003, Chang et al. 2005, Ratchford et al. 2008, Wang et al. 2010, Frank et al. 2014). It is therefore striking that good blastocyst ( $>40 \%$ ) and pregnancy rates $(>65 \%)$ have been reported in the horse by laboratories using both these media (Galli et al. 2007, Hinrichs et al. 2007, 2014, Smits \& Govaere 2010).

The mechanisms by which supraphysiological glucose causes downstream effects in oocytes and embryos of other species appear largely related to carbohydrate metabolism. We recently demonstrated that equine COCs are metabolically distinct from those of other mammals studied (Lewis et al. 2020). In that study, conducted in M199 media (5.6 mM glucose), we found that glycolysis was the major pathway of glucose metabolism; however, this made only a minor contribution to ATP production, and oxidative phosphorylation (OXPHOS) of mostly nonglycolytic substrates was responsible for the majority of ATP produced (Lewis et al. 2020).

Given the emerging evidence that nutrient provision during the periconceptual period can influence the lifelong health of the offspring (Watkins et al. 2008, Fleming et al. 2018), the aim of the present study was to compare the effect of the two commonly used glucose concentrations $(5.6 \mathrm{mM}$ and $17 \mathrm{mM})$ during IVM on equine COC energy metabolism. In addition, we evaluated the effects of these glucose concentrations during IVM on meiotic competence and developmental kinetics after ICSI, using our previously established methods (Lewis et al. 2019). We also examined the effects of the IVM environment on oocyte and cumulus cell gene expression, measuring the expression of genes coding for components of key metabolic pathways known to be affected by hyperglycaemia in other species (Colton et al. 2003, Chang et al. 2005, Ratchford et al. 2008, Wang et al. 2010). Finally, we assessed the relative expression of genes involved in mitochondrial biogenesis (Palmeira et al. 2007, Agarwal et al. 2012) and those encoding antioxidant enzymes, since oxidative stress is an additional regulator of the response to hyperglycaemia (Rolo \& Palmeira 2006).

\section{Materials and methods}

\section{General methods}

Ovaries were collected from mares of unrecorded age and breed and slaughtered during the natural breeding season (April-October) at a UK abattoir in compliance with EU legislation EC 852/2004, 853/2004, and 854/2004. Slaughter was carried out for reasons unrelated to the study. Ovaries were harvested within $15 \mathrm{~min}$ of slaughter and were processed in the laboratory within $9 \mathrm{~h}$. Cumulus-oocyte complexes were recovered by scraping the granulosa from opened follicles using a bone curette (Hinrichs \& DiGiorgio 1991) and classified as compact (Cp) or expanded (Ex) on the basis of cumulus morphology. Oocytes that had only corona radiata or were denuded of cumulus were excluded. Recovered COCs were placed in groups of ten in 1-mL glass vials in EH Medium (40\% M199 with Hanks salts, 40\% M199 with Earle's salts (Life technologies Ltd.), 20\% fetal bovine serum (FBS), and $25 \mu \mathrm{g} / \mathrm{mL}$ gentamicin; Choi et al. 2006). COCs were held overnight $(12-18 \mathrm{~h})$ at $20-24^{\circ} \mathrm{C}$. All maturation dishes, preprepared with $9-\mu \mathrm{L}$ droplets of experimental media covered with an oil overlay, were pre-equilibrated at $5 \% \mathrm{CO}_{2}$ in air at $38.3^{\circ} \mathrm{C}$ for $12 \mathrm{~h}$ before use. After addition of the COC in $1 \mu \mathrm{L}$ of medium, the final droplet size was $10 \mu \mathrm{L}$, which corresponds to the widely used medium to COC ratio of $10 \mu \mathrm{L}$ per COC (Hinrichs et al. 2005, Choi et al. 2009).

\section{Effect of glucose concentration during IVM on meiotic and developmental competence and glucose metabolism}

\section{Oocyte maturation}

To establish the validity of the IVM system used for the metabolic experiments, we followed the meiotic and developmental competence of all COCs in which metabolism was measured.

After the overnight holding period, COCs were washed in maturation medium and transferred singly in $1 \mu \mathrm{L}$ of medium, to each of the maturation droplets. Equal numbers of $\mathrm{Cp}$ and Ex COCs were used per experimental treatment. The treatments were Control (Maturation medium; M199 with Earle's salts, $10 \%$ FBS, $25 \mu \mathrm{g} / \mathrm{mL}$ gentamicin with $5 \mathrm{mU} / \mathrm{mL}$ FSH (Sioux Biochemical Inc., Sioux centre, IA)) or High Glucose (HG; 17 mM glucose; Maturation medium as previously mentioned, supplemented with an additional $11.4 \mathrm{mM}$ glucose. This raised the osmolarity by approximately 11.4 mosmol, which required approximately $3 \%$ dilution to ensure it was iso-osmolar with the control medium (290-300 mosmol). This in turn lowered the final glucose concentration to $16.5 \mathrm{mM}$, (rounded to $17 \mathrm{mM}$ throughout). There were 12 droplets per dish, three of these remained without COCs and served as reference droplets. The dishes were incubated in a humidified atmosphere of $5 \% \mathrm{CO}_{2}$ in air at $38.3^{\circ} \mathrm{C}$. After the 30-h maturation period, oocytes were denuded of cumulus in $80 \mathrm{IU} / \mathrm{mL}$ hyaluronidase. Denuded oocytes were evaluated by light microscopy at a magnification of $\times 500$ and classified as MII (polar body present), intact (intact oolemma without a polar body), or degenerated (DEG).

The cumulus cells removed from each MII oocyte were placed in wells of a 96-well plate and stored at $-20^{\circ} \mathrm{C}$ for later DNA quantification analysis as described by Sutton et al. (2003) as a proxy for the number of cumulus cells present. Spent media was frozen at $-80^{\circ} \mathrm{C}$ for substrate analysis (see subsequent section).

\section{ICSI and embryo culture}

ICSI and subsequent embryo culture was performed as described previously (Lewis et al. 2016). Embryos were cultured in DMEM/F12 with $10 \% \mathrm{FBS}$ and $25 \mu \mathrm{g} / \mathrm{mL}$ gentamicin as described (Hinrichs et al. 2005), with the exception that injected oocytes were placed in individual microwells within 
a $50-\mu \mathrm{L}$ droplet under oil on a plate manufactured for timelapse monitoring (Vitrolife). They were incubated at $38.3^{\circ} \mathrm{C}$ in $5 \% \mathrm{CO}_{2}, 5 \% \mathrm{O}_{2}$, and $90 \% \mathrm{~N}_{2}$ until blastocyst development (as defined below) or to a maximum of 10 days post ICSI. Images of each presumptive zygote were captured at 5-min intervals using the Primovision Time-Lapse System. Morphologic and morphokinetic analysis was performed on the resulting videos as previously described (Lewis et al. 2019). Briefly, zona pellucida thickness and oocyte diameter were measured on the first frame by taking the mean of at least two measurements of each. Time of cytoplasmic extrusion, first cleavage, and blastocyst formation was recorded for each injected oocyte when visualisation allowed, and this was complicated by the dark, opaque nature of the horse oocyte/embryo cytoplasm and movement due to remaining cumulus cells. Cytoplasmic extrusion, a phenomenon that appears to be physiological in the horse zygote and associated with competence for blastocyst development (Salgado et al. 2018, Lewis et al. 2019), was defined as the time cytoplasmic contents were first actively extruded from the oolemma. Time of first cleavage was defined as the time that the first visually identifiable indentation of the oolemma occurred, before a visualized cleavage. Embryos were classified as blastocysts on first appearance of apparent formation of a central fluid-filled cavity (blastulation). All annotations were performed by a single operator, blinded to oocyte treatment group.

\section{Analysis of glucose, lactate, and pyruvate content of spent medium}

In droplets that contained MII oocytes, changes in substrate concentrations were determined by comparison of concentrations in spent medium after IVM with those for medium from droplets cultured without embryos (Reference droplets). The frozen media samples were thawed and the concentrations of glucose, lactate, and pyruvate were measured using an enzyme-linked assay (Guerif et al. 2013). Briefly, the enzyme reaction mixture for each substrate (Guerif et al. 2013) was added to the 96-well assay plate first and background fluorescence was measured. Several sample dilutions (diluted with molecular grade water) were tested for each substrate assay in order to identify the dilution factor that gave the lowest co-efficient of variation (CV $<10 \%$ ), while conserving the initial sample volume. The diluted sample medium was then added to the enzyme reaction mixture and incubated at $37^{\circ} \mathrm{C}$ for 3,10 , or $30 \mathrm{~min}$ for pyruvate, glucose, and lactate, respectively, after which the change in fluorescence was recorded. This change in fluorescence was based on enzymatic reduction of $\mathrm{NADP}^{+}$(glucose), $\mathrm{NAD}^{+}$(lactate), or enzymatic oxidation of $\mathrm{NADH}$ (pyruvate). All measurements were made using a FLUOstar Omega spectrophotometer (BMG Labtech; Buckinghamshire, UK) set to excite samples at $340 \mathrm{~nm}$ and collect emission spectra at $460 \mathrm{~nm}$ using V-bottom, clear 96-well plates. All measurements were performed in triplicate (three wells per sample) and calibrated against a six-point standard curve of known concentrations of each substrate, freshly prepared before each individual assay. Measurements were subtracted from the mean of the empty Reference droplet readings and the mean of the triplicate measures calculated. Values were retained only if the technical triplicate CV was $<10 \%$.

\section{Effect of glucose concentration during IVM on mitochondrial oxidative metabolism}

Groups of three COCs were matched according to cumulus morphology (Cp or Ex) and cultured for IVM in Seahorse XFp Analyser plates (Agilent Technologies LDA UK Ltd) in $180 \mu \mathrm{L}$ of either Control or $\mathrm{HG}$ maturation medium in $5 \% \mathrm{CO}_{2}$ in air. Basal oxygen consumption rate (OCR) and mitochondrial function parameters (OCR coupled to ATP production, OCR associated with proton leak, non-mitochondrial OCR, and spare respiratory capacity) were determined at $28 \mathrm{~h}$ of culture using an Agilent Seahorse XFp analyser, as described (Muller et al. 2019).

To do this, COCs were incubated for an initial 12-min calibration phase, before taking three basal readings of OCR. This was followed by the sequential addition of: (1.) Oligomycin $(1 \mu \mathrm{M})$, an inhibitor of ATP synthase which decreases OCR to that not linked to ATP synthesis by oxidative phosphorylation; (2.) FFCP $(5 \mu \mathrm{M})$, a proton ionophore which uncouples the flow of protons across the mitochondrial membrane from the normal restricted rate of passage though Complex $V$ (ATP synthase), thus allowing maximal OCR to occur and enabling the calculation of 'spare capacity' as the difference between this value and the resting OCR; and (3.) Antimycin and rotenone (2.5 $\mu \mathrm{M}$ of each) which inhibit the quinone reduction (Qi) site in Complex III and Complex I of the electron transport chain, respectively, thereby blocking mitochondrial OXPHOS and leaving only the proportion of OCR due to non-mitochondrial processes such as the production of radical oxygen species (ROS) and oxygen-consuming enzymes. The difference between the ATP coupled OCR and non-mitochondrial OCR is known as 'proton leak' and is defined as protons moving back into the mitochondrial matrix but not through ATP synthase (Represented schematically in Fig. 4A).

\section{Effect of glucose concentration during IVM on oocyte and cumulus gene expression}

In vitro maturation was carried out in either Control or HG maturation medium as described, in individual $10-\mu \mathrm{L}$ droplets. Glucose, lactate, and pyruvate analyses were performed on spent media of MII oocytes as previously described. Denuded MII oocytes, and a sample of their corresponding cumulus, were subjected separately to RNA extraction and cDNA preparation. To the best of our knowledge there is no information on the analysis of Poly-A tailed cDNA in equine cumulus cells or oocytes, thus the methods developed are presented in detail. The PolyA PCR technique used was based on that described previously (Brady \& Iscove 1993, Bloor et al. 2002). The concentration of the resulting amplified cDNA was quantified using the Quant- IT, Picogreene kit (Life Technologies). Six reference genes were tested for suitability in six oocyte and six cumulus cell samples (RPL32, UBC, ACTB, SRP14, HPRT1, and SDHA). qPCR reactions were made up as follows and plated in duplicate: $5 \mu \mathrm{L}$ cDNA (5 ng), $1 \mu \mathrm{L}$ primer, $10 \mu \mathrm{L}$ PrecisionPlus mastermix (Primerdesign LTD), 
and $4 \mu \mathrm{L}$ PCR water. Amplification was performed on a Roche Lightcycler 480 using the following protocol: initial enzyme denaturation of $2 \mathrm{~min}$ at $95^{\circ} \mathrm{C}$, then 40 cycles of $10 \mathrm{~s}$ at $95^{\circ} \mathrm{C}$ and $60 \mathrm{~s}$ at $60^{\circ} \mathrm{C}$. Post-PCR melt curves were run for each gene to test specificity, and the gene was excluded from analysis if more than one peak existed. Online combination software RefKeeper was used to determine the stability across four different validated reference gene selection platforms. RPL32 and UBC were repeatedly the most stable and both were chosen for further stability testing during target gene qPCR.

Seven genes of interest and the two reference genes were investigated. Taqman probe-based primers were designed within $300 \mathrm{bp}$ of the polyA tail at the 3' UTR (Primerdesign LTD, Chandler's Ford, UK; Supplementary Table 1, see section on supplementary materials given at the end of this article). All primers were validated and QC tested by the designing company. qPCR reactions were made up as follows and plated in triplicate; $5 \mu \mathrm{L}$ CDNA (5 ng), $1 \mu \mathrm{L}$ primer, $10 \mu \mathrm{L}$ PrecisionPlus mastermix (Primerdesign LTD), and $4 \mu \mathrm{L}$ PCR water. Amplification was performed on a Biorad CFX using the following protocol: initial enzyme denaturation of $2 \mathrm{~min}$ at $95^{\circ} \mathrm{C}$, then 50 cycles of $15 \mathrm{~s}$ at $95^{\circ} \mathrm{C}$ and $60 \mathrm{~s}$ at $60^{\circ} \mathrm{C}$. Data were collected through the FAM channel at the final stage. Reference genes were run for each sample on each plate. In cumulus cells, RPL32 showed higher expression in all samples (mean Ct 19.5 vs 23.4 for $U B C$ ) and also less variation (s.D. 2.9 and CV $15 \%$ vs 4.8 and $20 \%$ for UBC), thus RPL32 was used to calculate $\triangle C$ t values. In oocytes, UBC showed higher expression in all samples (mean Ct 20.8 vs 23.9 for RPL32) and also less variation (s.D. 3.6 and CV $17 \%$ vs 45.3 and $22 \%$ for RPL32), consequently UBC was used to calculate $\triangle \mathrm{Ct}$ values. The mean $\mathrm{Ct}$ value from each technical triplicate was calculated for each sample and retained if variation was $<1 \mathrm{Ct}$. Ct values over 36 with high technical variation were assumed to be not expressed. $\Delta$ Ct was then calculated for each sample by subtracting the $\mathrm{Ct}$ value of the reference gene of that sample (from that plate) from the Ct value of the gene of interest.

\section{Statistical analysis}

\section{Substrate consumption/production}

The primary outcome variables were glucose consumption, lactate production, and pyruvate production, expressed as mean values in pmol/ngDNA/h. All data for substrate consumption/production were expressed as a function of the amount of DNA in the associated cumulus cells as a proxy for the cumulus cell number as previously reported for equine COCs (Lewis et al. 2020). Glycolytic index was calculated as the ratio of lactate production/glucose consumption, with a value of 2 considered to represent $100 \%$. Data were first tested for normality using the Shapiro-Wilk test, then the MannWhitney $U$ test was used to determine differences between conditions and $P$ values $<0.05$ were assumed to indicate significance. Five replicates were performed.

\section{$\mathrm{O}_{2}$ consumption rate measurement}

The third reading was used for all basal OCR measurements and that representing maximal response was used for all inhibitor
OCR values. Data were expressed as $\mathrm{pmolO}_{2} / \mathrm{COC} / \mathrm{h}$ or $\mathrm{pmolO}_{2} / \mathrm{ngDNA} / \mathrm{h}$. Percentage data were arcsine transformed before being tested for normality using the Shapiro-Wilk test. Student's $t$-test was then used to assess differences between conditions. Three replicates were performed.

\section{Gene expression}

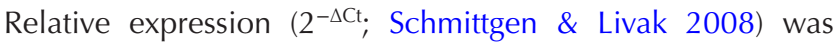
compared across experimental groups for genes that were ubiquitously expressed using the Mann-Whitney $U$ test. Three replicates were performed.

\section{Results}

\section{Validation of efficacy of IVM system}

In total, 176 COCs were subjected to IVM culture. There were no significant differences in (1.) the proportion of oocytes reaching metaphase II (51 and 62.5\%) or (2.) cleavage or blastocyst development rates between control and HG treatments (Table 1). Evaluation of morphologic and morphokinetic parameters in injected MII oocytes $(n=83)$ showed no difference in developmental timing or morphology between embryos from the two treatment groups (Fig. 1). We concluded that both systems were equally effective in terms of supporting meiotic and developmental competence and were thus valid to use for evaluation of COC metabolic parameters.

\section{Glucose concentration during IVM did not affect COC glucose, pyruvate, or lactate flux but did modify the glycolytic index}

Analysis of spent medium revealed that 18\% (9/50) of MII COCs in the Control treatment depleted all glucose in the culture medium droplet; however, none of the COCs in the HG treatment did so. Within the Control treatment, depletion of all available glucose during IVM was associated with a higher total DNA content, indicating a larger number of cumulus cells (155.13 ng, vs $99.18 \mathrm{ng}$ for non-depleting COC; $P<0.01)$. Depletion of all glucose did not affect cleavage or blastocyst rates after ICSI (Table 2) and there was no apparent effect of glucose depletion during IVM on the four morphologic and morphokinetic parameters (data not shown). COCs that depleted all glucose consumed more glucose (12.67 vs $9.99 \mathrm{pmol} / \mathrm{ng} \mathrm{DNA} / \mathrm{h})$, had a significantly decreased

Table 1 Effect of glucose concentration (5.6 mM vs $17 \mathrm{mM}$ ) during equine IVM on maturation, cleavage, and blastocyst rate per injected oocyte post ICSI.

\begin{tabular}{lccc}
\hline & \multicolumn{2}{c}{ IVM } & \multirow{2}{*}{$\boldsymbol{P}$} \\
\cline { 2 - 3 } & $5.6 \mathrm{mM}$ Glucose & $17 \mathrm{mM}$ Glucose & $\boldsymbol{P}$ \\
\hline Maturation rate & $62.5 \%(55 / 88)$ & $51 \%(45 / 88)$ & 0.13 \\
Cleavage rate & $75.5 \%(37 / 49)$ & $76.5 \%(26 / 34)$ & 0.92 \\
Blastocyst rate & $8.2 \%(4 / 49)$ & $2.9 \%(1 / 34)$ & 0.4 \\
\hline
\end{tabular}



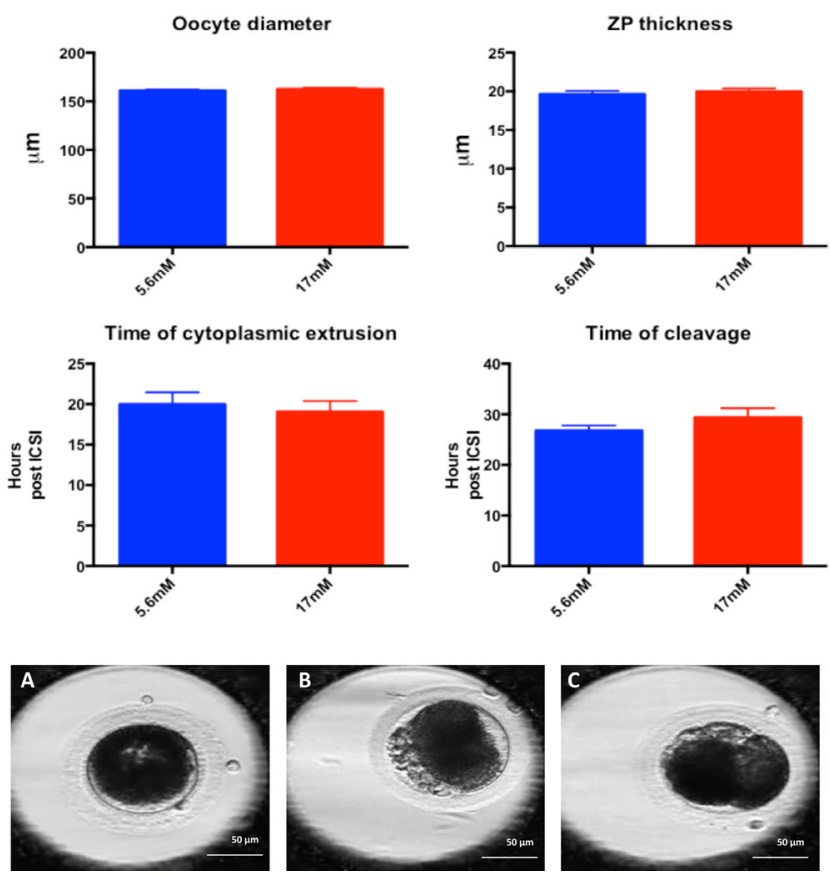

Figure 1 Effect of glucose concentration $(5.6 \mathrm{mM}$ and $17 \mathrm{mM})$ during equine IVM on morphokinetic parameters measured using the Primovision Time-lapse system. All injected MII oocytes were analysed ( $n=83,5$ replicates); however, cytoplasmic extrusion and cleavage determination was only possible for 37 and 48 oocytes, respectively, due to the opacity of the cytoplasm, loss of focus due to excess oocyte movement, and/or presence of adherent cumulus cells. Bars represent mean \pm S.E.M. Insert panel B shows representative photomicrographs (Brightfield 300X) taken with the Primovision camera of uncleaved oocyte (A), cytoplasmic extrusion (B), and first cleavage (C).

glycolytic index (lactate: glucose ratio of 1.17 vs 2.12 ), and produced significantly less pyruvate $(0.23$ vs 0.73 $\mathrm{pmol} / \mathrm{ng} \mathrm{DNA} / \mathrm{h} ; P=0.01$; Table 2) compared to those for which glucose did not become limiting.

In subsequent analyses, those COCs that depleted all glucose from the culture droplet were excluded from further comparisons. In the remaining COCs (i.e. those for which glucose did not become limiting) there were no significant differences between Control and HG treatments in glucose consumption $(9.99 \pm 1.11$ vs $11.14 \pm 1.37 \mathrm{pmol} / \mathrm{ng} \mathrm{DNA} / \mathrm{h}$, respectively) or in lactate $(18.39 \pm 1.82$ vs $14.08 \pm 1.40 \mathrm{pmol} / \mathrm{ng} \mathrm{DNA} / \mathrm{h}$, respectively) or pyruvate $(0.73 \pm 0.09$ vs $0.76 \pm 0.22$ $\mathrm{pmol} / \mathrm{ng} \mathrm{DNA} / \mathrm{h}$, respectively) production (Fig. 2). There was, however, a decreased glycolytic index in the HG treatment (Fig. 2C).

We observed no association between glucose consumption, lactate production, cleavage, or blastocyst rate (Fig. 3), although the number of embryos generated was low. Glucose consumption during IVM of the three non-depleting COCs that yielded blastocysts were 13.08. 10.03, and $6.84 \mathrm{pmol}$ glucose/ngDNA/h and these same three COCs released 14.41, 21.59, and 20.97 pmol lactate/ng DNA/h, respectively. The mean glucose consumption for COCs that did not go on to form a blastocyst was $10.37 \mathrm{pmol} / \mathrm{ng} / \mathrm{DNA} / \mathrm{h}$ and mean lactate production was $18.74 \mathrm{pmol} / \mathrm{ng} \mathrm{DNA} / \mathrm{h}$.

\section{Glucose concentration during IVM altered mitochondrial function but did not affect basal COC OCR}

The OCR of 54 COCs was measured. Since COCs were cultured in groups of three in excess maturation medium $(60 \mu \mathrm{L}$ per COC) for a limited time, no depletion of glucose was anticipated. Basal OCR did not differ significantly between the two glucose treatments $(47.1 \pm 8.1$ and $35.1 \pm 7.1 \mathrm{pmol} \mathrm{O}_{2} / \mathrm{ng} \mathrm{DNA} / \mathrm{h}$ for control and $\mathrm{HG}$, respectively; Fig. 4B). Evaluation of mitochondrial respiratory chain function revealed significant differences between the two glucose treatments (Fig. 4C). The proportion of OCR sensitive to oligomycin, and thus coupled to ATP production, was reduced in COCs matured in HG $(62 \pm 4.8 \%$ vs $42 \pm 5.3 \%$ in HG; $P=0.01)$, while non-mitochondrial OCR was elevated in these COCs $(26 \pm 6.1 \%$, vs $48 \pm 6 \%$ in HG; $P=0.02)$.

\section{Glucose concentration during IVM affected expression of one of six genes evaluated in cumulus cells of MII oocytes}

Twenty-eight COCs were placed in either control or HG media for IVM as described previously and gene expression in MII oocytes $(n=6$ in control group and $n=7$ in HG) and a sample of their corresponding cumulus cells were determined. On analysis of the spent medium in the associated maturation droplets,

Table 2 Mean ( \pm S.E.M.) substrate consumption and production rates and developmental markers (cleavage and blastocyst rate) for equine Metaphase II COCs that depleted all available glucose during IVM and those that did not.

\begin{tabular}{lccc}
\hline & Depleted $(n=9)$ & Undepleted $(n=41)$ & \multicolumn{1}{c}{} \\
\hline Glucose consumption rate $(\mathrm{pmol} / \mathrm{ng} \mathrm{DNA} / \mathrm{h})$ & $12.67 \pm 0.97$ & $9.99 \pm 1.11$ & $0.03^{*}$ \\
Lactate production rate $(\mathrm{pmol} / \mathrm{ng} \mathrm{DNA} / \mathrm{h})$ & $15.06 \pm 1.56$ & $18.39 \pm 1.82$ & 0.7 \\
Pyruvate production rate $(\mathrm{pmol} / \mathrm{ng} \mathrm{DNA} / \mathrm{h})$ & $0.23 \pm 0.08$ & $0.73 \pm 0.09$ & $0.004^{*}$ \\
Lactate: glucose ratio & $1.17 \pm 0.07$ & $2.12 \pm 0.17$ & $<0.001^{*}$ \\
Cleavage rate & $66.7 \%(6 / 9)$ & $77.5 \%(31 / 40)$ & 0.5 \\
Blastocyst rate & $11.1 \%(1 / 9)$ & $7.5 \%(3 / 40)$ & 0.7 \\
\hline
\end{tabular}

*Denotes statistical significance at $P<0.05$, Mann-Whitney $U$ test. 
A

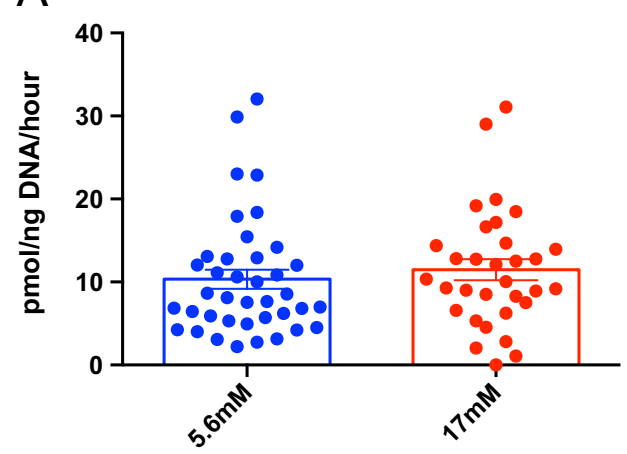

B
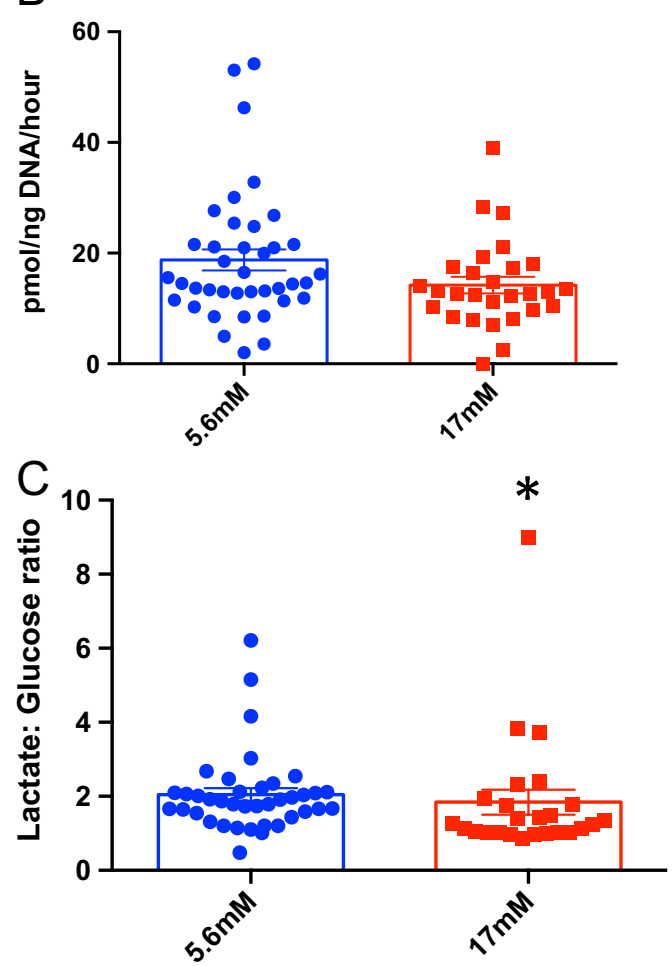

D Pyruvate production

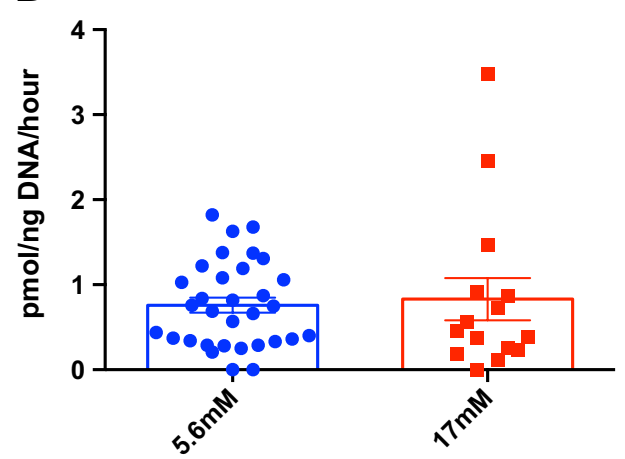

Figure 2 Effect of glucose concentration (5.6 mM vs $17 \mathrm{mM}$ ) during IVM on glucose consumption (A), lactate production (B), lactate: glucose ratio $(\mathrm{C})$, and pyruvate production $(\mathrm{D})$. Bars represent mean \pm S.E.M. Data points represent individual COCs. $(n=80 \mathrm{MII}$ COCs, 5 replicates). ${ }^{*}$ denotes significance $(P<0.05$; Mann-Whitney $U$ test).
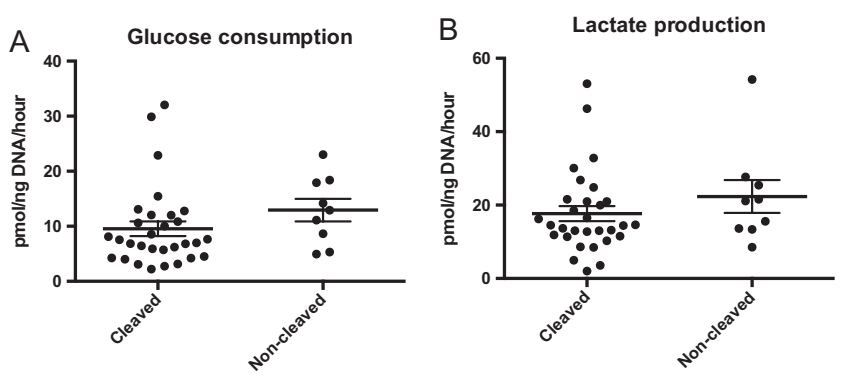

Figure 3 Glucose consumption rates (Panel A) and lactate production rates (Panel B) during IVM plotted around the mean \pm S.E.M. $(n=41$ injected oocytes in Control glucose group $(5.6 \mathrm{mM})$ that did not deplete all available glucose during IVM, over 5 replicates). Cleaved vs un-cleaved oocytes at $48 \mathrm{~h}$ are compared (A and B). No statistically significant differences were found between groups (Mann-Whitney $U$ test). Data points represent individual COCs.

$2 / 6$ of the COCs in the Control group had depleted all available glucose. However, there were no notable differences in gene expression between these oocytes and the remainder of the Control oocytes, such that all
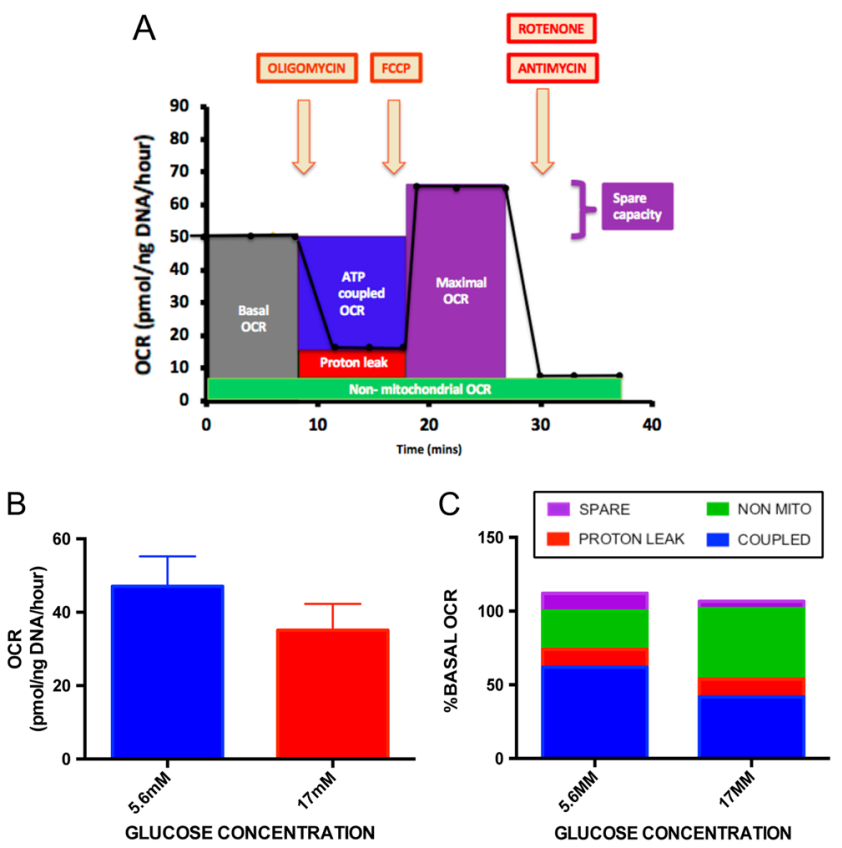

Figure 4 Schematic diagram depicting how each of the mitochondrial function parameters is derived through the sequential addition of respiratory inhibitors (A). Effect of glucose concentration during IVM on basal OCR (B; $n=54,3$ replicates). Mean \pm S.E.M. is presented. Effect of glucose concentration during IVM on mitochondrial function as determined by sequential addition of respiratory inhibitors (C; $n=54,3$ replicates). $\mathrm{O}_{2}$ consumption rate (OCR) coupled to ATP production (BLUE), OCR associated with proton leak (RED), non-mitochondrial OCR (GREEN), and spare respiratory capacity (PURPLE) are expressed as \% basal OCR. Means are stacked. Significant differences between glucose concentrations existed in OCR coupled to ATP (BLUE) and non-mitochondrial OCR (GREEN) $P=0.02$; Students $t$-test. 
COCs in the Control group were evaluated together. For clarity, on the resulting dot-plots (Fig. 5A and B) the results from glucose-depleted oocytes and cumulus are highlighted clearly.

In oocytes, the expression of the metabolically important genes GPX1, LDHA, G6PD, PKFM, TFAM, or SLC2A1 was not affected by maturation in HG conditions (Fig. 5A). Across all oocytes, GPX1 and LDHA were highly, and G6PD moderately, expressed in most samples. TFAM was expressed in only one oocyte, in the 5.6-mM treatment, and SLC2A1 in one oocyte from each treatment.

In cumulus cells, expression of $\angle D H A$ was significantly reduced in COCs matured in HG conditions $(P<0.05$, Fig. 5B). Over both glucose groups, the genes GPX1, $\angle D H A$, and G6PD showed high relative expression and were detected in all samples, while PFKM was moderately and TFAM and SLC2A1 poorly expressed in a subset of cumulus samples (Fig. 5B).

\section{Discussion}

The effect of supraphysiological glucose concentration during IVM on oocytes, COCs, and embryos from a number of mammalian species has been well described (reviewed by Frank et al. 2014); however, this is the first report to directly investigate a biochemical effect of high glucose during IVM in equine COCs. This work has revealed that high glucose during IVM did not influence overall glucose consumption, lactate and pyruvate production, or basal OCR. However, we found that maturation in an elevated glucose concentration caused a decrease in glycolytic index and a significant modification in mitochondrial function. Using extracellular flux analysis, we showed that culture in $17 \mathrm{mM}$ glucose caused a reduction in ATPcoupled respiration and increase in non-mitochondrial respiration compared to culture at physiological glucose concentrations. We also found that this environment resulted in changes in a component of the equine cumulus cell transcriptome; specifically, that LDHA was downregulated in cumulus cells after IVM in 1 7-mM glucose.

Studies in mice and cattle have demonstrated a paradoxical reduction in glucose uptake by COCs and embryos in hyperglycaemic conditions; a finding attributed to down-regulation of glucose transporters (Sutton-McDowall et al. 2010, Wang et al. 2010, 2012, Frank et al. 2014). In contrast, in the present study, glucose concentration had no significant effect on glucose consumption in equine oocytes, and notably, expression of SLC2A1 was not downregulated in response to high glucose. On this basis, we propose that COC and embryo glucose tolerance are, to some extent,

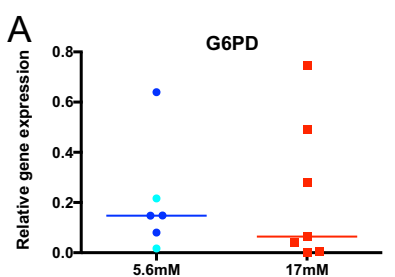

SLC2A1

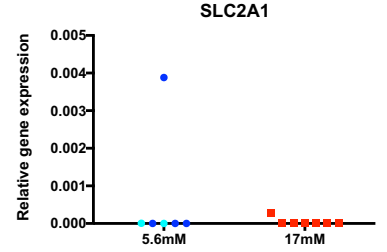

B
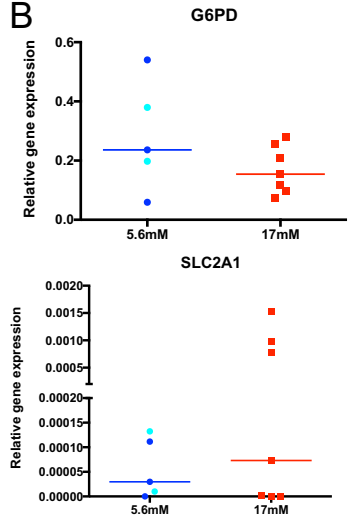

https://rep.bioscientifica.com
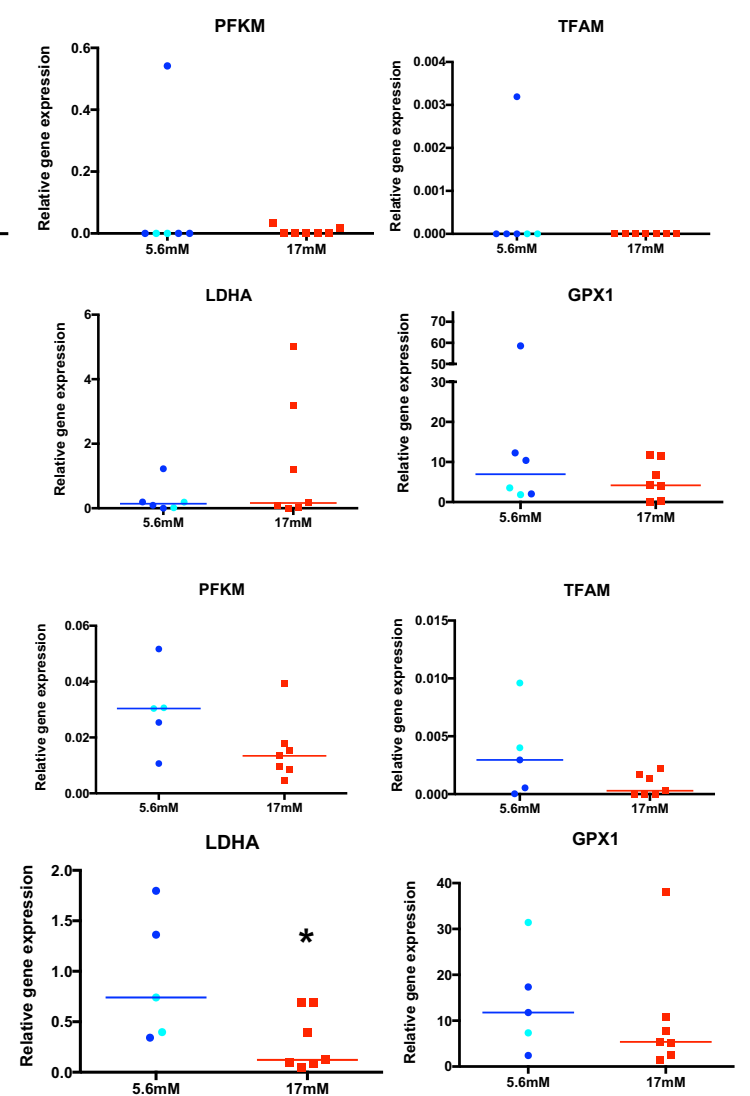

Figure 5 Effect of glucose concentration (5.6 $\mathrm{mM}$ vs $17 \mathrm{mM}$ ) during IVM on relative gene expression of each gene in oocytes $(n=13,3$ replicates normalised against UBC, Panel A) and cumulus cells $(n=12,3$ replicates normalised against RPL32, Panel B) across all experimental groups. The median is presented. Asterisk represents significant difference $(P<0.05$; Mann-Whitney $U$ test). Two COCs in the control group depleted all available glucose during IVM and are highlighted separately in light blue. 
species specific. Data for embryos are included in this assertion, and while hyperglycaemia in early embryo culture dramatically reduces embryo development in the mouse, hamster, sheep, and cow (Chatot et al. 1989, Seshagiri \& Bavister 1989, Thompson et al. 1992, Furnus et al. 1997), porcine and equine embryos develop normally in glucose concentrations as high as $20 \mathrm{mM}$ (Sturmey \& Leese 2003, Choi et al. 2015). It is possible that glucose transporters in the COC have different sensitivities in different species. Interestingly, this was suggested in a study on lamellar explants of the equine hoof: glucose uptake increased up to a concentration of $15 \mathrm{mmol} / \mathrm{L}$ and fell as a result of GLUT1 downregulation only when the concentration reached $21 \mathrm{mmol} / \mathrm{L}$ (Asplin et al. 2011). In contrast, human keratinocytes showed a decrease in glucose uptake at $4 \mathrm{mM}$ glucose (Spravchikov et al. 2001). While glucose transport properties obviously vary between tissues, the study by Asplin lends weight to the hypothesis that concentrations of glucose higher than those used in the present study may be required in the equine COC/embryo to cause a decrease in glucose uptake.

The apparent glucose tolerance displayed by horse oocytes is even more fascinating, given that glucose homeostasis in the adult horse is tightly controlled. Serum glucose levels are maintained between 4.9 and $6.2 \mathrm{mM}$ and, contrary to findings in other species, insulin resistance associated with diseases such as obesity and metabolic syndrome is characterised by secondary hyperinsulinaemia such that hyperglycaemia does not occur in the horse. In contrast, in human insulin resistance, pancreatic exhaustion occurs leading to decreased insulin secretion and hyperglycaemia as in type-2 diabetes (Morgan et al. 2015). Clinical hyperglycaemia in the horse is only found at the end stage of diseases, such as sepsis, when death is imminent (Hollis et al. 2007). Thus, the equine COC and embryo would never experience systemic hyperglycaemia in vivo. We therefore postulate that because the horse will only very rarely be in a hyperglycaemic state, the COC and embryo lack the ability to mount a response to hyperglycaemia to adjust glucose transport.

The main aim of this research was to investigate the metabolic effects of high glucose concentration during IVM; however, blastocyst production as an indicator of developmental competence was also evaluated. While the blastocyst rate was low, it is within the range previously published for the horse (Galli et al. 2007, Smits \& Govaere 2010, Lewis et al. 2016). Given the existing clinical literature that both of these glucose concentrations - used by different laboratories - support oocyte maturation and embryo development with apparently similar blastocyst rates and production of live offspring in the horse (Galli et al. 2007, Hinrichs et al. 2007, 2014, Smits \& Govaere 2010), our study was not designed to assess development to blastocyst. Rather, our data have revealed changes in the metabolic physiology of the COCs in response to exposure to high glucose, and the impact of these modifications warrants further investigation.

We previously reported that under current standard clinical conditions for IVM, that is, $5.6 \mathrm{mM}$ glucose, at a ratio of $10-\mu \mathrm{L}$ medium per oocyte, a proportion of equine COCs deplete all the available glucose during IVM (Lewis et al. 2020). We explored this phenomenon further in the present study, evaluating potential downstream effects of glucose exhaustion. While the depletion of glucose during maturation and thus lack of glucose at the end of maturation might suggest the possibility of compromised COC physiology, the developmental data in the present study indicated otherwise. Of the nine MII oocytes associated with COC that depleted all glucose, one formed a blastocyst after ICSI. However, the greatly reduced glycolytic index found for these COCs $(60 \%$ vs $95 \%$ ) indicates a significant metabolic response and an alteration in the pathways used for ATP production. While glucose depletion from the droplet is partly a function of having more cumulus cells, the observations suggest that some COCs have an intrinsically different strategy for glucose metabolism to others. Further work is required to examine the causes and consequences of glucose depletion, particularly focusing on wider impact of any metabolic compensation. Interestingly, the glucose consumption of those COCs that cleaved and formed blastocysts was very close to the mean of all COCs and supports the 'Goldilocks principle' of Leese, which posits that maximal development is achieved when the metabolic rate is 'just right' (Leese et al. 2016). However, since it seems likely that glucose concentration becomes exhausted in many routine clinical programmes, it seems prudent at this time to conclude that culture conditions should be adjusted to prevent the COC from depleting all available glucose. While culture in high glucose did prevent glucose exhaustion, other more physiological methods such as tight trimming of excess granulosa and increasing the COC:medium ratio to $15 \mu \mathrm{L}$ per COC may be more compatible with maintenance of normal mitochondrial function (Lewis et al. 2020).

Our measurements of OCR revealed a decrease in ATPcoupled OCR and associated increase in the proportion of non-mitochondrial respiration in COCs matured in the presence of 17-mM glucose. Such observations might indicate compromised mitochondria and increased ROS production. Parallel observations have been reported in bovine and murine oocytes and in murine somatic cells exposed to high glucose levels (Hashimoto et al. 2000, Rolo \& Palmeira 2006, Wang et al. 2010). Indeed, uncoupling protein (UPC) expression in the inner mitochondrial membrane is known to be responsive to the effects of excess glucose in somatic cells, as a way to compensate for the increased ROS production (Cui et al. 2006, Koziel et al. 2015). This suggests a possible mechanism by which the decreased glycolytic 
index observed in COCs in the 17-mM group in the current study resulted in excess glucose contributing to increased UPC expression and thus decreased coupled OCR. Interestingly, consistently lower ATP levels were reported in murine oocytes and cumulus cells as a sequela to hyperglycaemia (Colton et al. 2003, Chang et al. 2004, Wang et al. 2010, 2012). In the current study, the basal OCR did not differ significantly between treatments; however, the ATP-linked proportion was significantly decreased in the $17-\mathrm{mM}$ treatment. On this basis, we conclude that the high glucose treatment resulted in decreased ATP production from oxidative processes, which again points to a metabolic adaptation to supraphysiological glucose. It is possible that this metabolic adaptation in mitochondrial function may have long-term consequences. Current clinical data suggest that at least blastocyst rate and foal production are essentially equivalent for oocytes matured at either glucose concentration (Galli et al. 2007, Hinrichs et al. 2007, 2014, Smits \& Govaere 2010). This indicates that the equine COC is able to adapt to culture conditions; however, as reviewed by Roseboom (2018), such an adaptation can occur to the detriment of long-term health outcomes; indices which have yet to be examined for foals produced by equine ART. Ideally, such an examination would involve phenotyping foals produced from various conditions. An interesting study by Valenzuela et al. (2018) found no significant differences in the effects of equine-assisted reproduction techniques (embryo transfer and ICSI) on foal and placenta morphometry or expression of selected placental genes, despite the markedly poorer success rate of clinical ART. Recent data from Walter et al. (2019) proposed that a significantly modified protein and metabolite profile of cumulus cell activity between in vitro and in vivo matured oocytes was the cause of the poorer success rates of clinical ART in the horse. Given that mitochondria are central to any metabolic response and that the equine embryo is reliant on oocyte mitochondria until mitochondrial replication resumes at the blastocyst stage (Hendriks et al. 2018), mitochondrial dysfunction has the potential to affect development adversely. Mitochondrial dysfunction has been implicated in aneuploidy, and fertilisation has an absolute requirement for a highly polarised mitochondrial membrane to sustain calcium oscillations (Dumollard et al. 2004). Notably, aberrations in both these processes even for a short period around the time of fertilization can affect long-term development and metabolic programming (Banrezes et al. 2011). In the horse, adult metabolic diseases such as laminitis, obesity, equine metabolic syndrome, and Cushing's disease are of increasing and significant clinical importance, and as such, potential metabolic changes due to glucose concentration during IVM should be evaluated further in terms of possible effects on the resulting offspring.
To uncover a molecular component of the observed metabolic phenotypes, we measured the expression of a panel of genes involved in the regulation of metabolic pathways. We report the expression of G6PD in both equine oocytes and cumulus cells and the expression of TFAM in equine cumulus cells. We found that GPX1, $\angle D H A$, and G6PD were highly expressed in most samples; however, there was sporadic expression of the other genes (PFKM, SLC2A1, and TFAM). Notably, $\angle D H A$, the enzyme that catalyses the bidirectional conversion of pyruvate and L-lactate, was significantly downregulated in cumulus cells isolated from COCs matured in 17-mM glucose medium. While we did not see a fall in lactate production, this finding does support the observation of decreased glycolytic index on a per-oocyte basis and thus potential glucose build up if not used in other pathways. Further studies would be required to identify the fate of the excess glucose.

In summary, the results of this investigation suggest that the use of $17-\mathrm{mM}$ glucose medium for equine IVM alters the metabolic fate of glucose, mitochondrial metabolism, and the expression of key metabolic genes. Our data show that the novel combination of extracellular flux analysis and substrate depletion assays can be used to generate metabolic profiles of glucose metabolism and mitochondrial function in intact individual COCs, with the ability to assess the meiotic and developmental potential of the associated oocytes. We used these methods in an equine model in combination with ICSI to accomplish fertilisation. Using this approach, we have been able to demonstrate that the medium used for IVM changes equine COC metabolism. Such data are important in informing approaches to design media better suited for equine ART; something that is crucial in the context of developmental determinants of long-term health (EI Hajj \& Haaf 2013), particularly in domestic horses, which have a long career with varied demands placed upon them.

\section{Supplementary materials}

This is linked to the online version of the paper at https://doi. org/10.1530/REP-20-0032.

\section{Declarations of interest}

The authors declare that there is no conflict of interest that could be perceived as prejudicing the impartiality of the research reported.

\section{Funding}

This work was supported by the BBSRC (iCASE studentship number: 1510626, 2014). 


\section{Author contribution statement}

$\mathrm{N} \mathrm{L}, \mathrm{C} \mathrm{A}, \mathrm{KH}$, and D R B designed the project and obtained the funding. $\mathrm{KH}, \mathrm{H} J \mathrm{~L}, \mathrm{D} R \mathrm{~B}$, and R G S supervised the study and $\mathrm{N} L$ carried out the experimental work. $N \mathrm{~L}$ wrote the manuscript, which was edited by $\mathrm{KH}, \mathrm{H} \mathrm{J} \mathrm{L}, \mathrm{D} \mathrm{R} \mathrm{B}$, and R G S.

\section{Acknowledgements}

The authors would like to thank Twemlows Stud Farm for supporting the research carried out in this paper and Stephen Potter for his continued support of equine research. The authors would also like to thank Bethany Muller, Andrew Gordon, Kalliopi Roussi, Paul McKeegan, and Constantine Simintiras from the Sturmey Laboratory and Helen Smith and Wedad Aboussahoud from the Maternal and Fetal Research Centre for technical advice and scientific discussion and Karen Schnauffer for performing ICSI.

\section{References}

Agarwal A, Aponte-Mellado A, Premkumar BJ, Shaman A \& Gupta S 2012 The effects of oxidative stress on female reproduction: a review. Reproductive Biology and Endocrinology 10 49. (https://doi. org/10.1186/1477-7827-10-49)

Asplin KE, Curlewis JD, Mcgowan CM, Pollitt CC \& Sillence MN 2011 Glucose transport in the equine hoof. Equine Veterinary Journal 43 196-201. (https://doi.org/10.1111/j.2042-3306.2010.00127.x)

Banrezes B, Sainte-Beuve T, Canon E, Schultz RM, Cancela J \& Ozil JP 2011 Adult body weight is programmed by a redox-regulated and energy-dependent process during the pronuclear stage in mouse. PLoS ONE 6 e29388. (https://doi.org/10.1371/journal.pone.0029388)

Bloor DJ, Metcalfe AD, Rutherford A, Brison DR \& Kimber SJ 2002 Expression of cell adhesion molecules during human preimplantation embryo development. Molecular Human Reproduction 8 237-245. (https://doi.org/10.1093/molehr/8.3.237)

Brady G \& Iscove NN 1993 Construction of cDNA libraries from single cells. Methods in Enzymology 225 611-623. (https://doi.org/10.1016/00766879(93)25039-5)

Brom-de-Luna JG, Salgado RM, Canesin HS, Diaw M \& Hinrichs K 2019 Equine blastocyst production under different incubation temperatures and different $\mathrm{CO} 2$ concentrations during early cleavage. Reproduction, Fertility, and Development 31 1823-1829. (https://doi.org/10.1071/ RD19211)

Chang AS, Chi MM \& Moley KH 2004 Maternal hyperglycaemia adversly affects pre-ovulatory oocyte metabolism. Fertility and Sterility 82 S269. (https://doi.org/10.1016/j.fertnstert.2004.07.719)

Chang AS, Dale AN \& Moley KH 2005 Maternal diabetes adversely affects preovulatory oocyte maturation, development, and granulosa cell apoptosis. Endocrinology 146 2445-2453. (https://doi.org/10.1210/ en.2004-1472)

Chatot CL, Ziomek CA, Bavister BD, Lewis JL \& Torres I 1989 An improved culture medium supports development of random-bred 1-cell mouse embryos in vitro. Journal of Reproduction and Fertility 86 679-688. (https://doi.org/10.1530/jrf.0.0860679)

Choi YH, Varner DD, Hartman DL \& Hinrichs K 2006 Blastocyst production from equine oocytes fertilized by intracytoplasmic injection of lyophilized sperm. Animal Reproduction Science 94 307-308. (https:// doi.org/10.1016/j.anireprosci.2006.03.085)

Choi YH, Harding HD, Hartman DL, Obermiller AD, Kurosaka S, McLaughlin KJ \& Hinrichs K 2009 The uterine environment modulates trophectodermal POU5F1 levels in equine blastocysts. Reproduction 138 589-599. (https://doi.org/10.1530/REP-08-0394)

Choi YH, Ross P, Velez IC, Macías-García B, Riera FL \& Hinrichs K 2015 Cell lineage allocation in equine blastocysts produced in vitro under varying glucose concentrations. Reproduction 150 31-41. (https://doi. org/10.1530/REP-14-0662)
Claes A, Cuervo-Arango J, van den Broek J, Galli C, Colleoni S, Lazzari G, Deelen C, Beitsma M \& Stout TA 2019 Factors affecting the likelihood of pregnancy and embryonic loss after transfer of cryopreserved in vitro produced equine embryos. Equine Veterinary Journal 51446-450. (https://doi.org/10.1111/evj.13028)

Collins A, Palmer E, Bézard J, Burke J, Duchamp G \& Buckley T 1997 A comparison of the biochemical composition of equine follicular fluid and serum at four different stages of the follicular cycle. Equine Veterinary Journal: Supplement 25 12-16. (https://doi. org/10.1111/j/2042-3306.1997.tb05092.x)

Colton SA, Humpherson PG, Leese HJ \& Downs SM 2003 Physiological changes in oocyte-cumulus cell complexes from diabetic mice that potentially influence meiotic regulation. Biology of Reproduction 69 761-770. (https://doi.org/10.1095/biolreprod.102.013649)

Cui Y, Xu X, Bi H, Zhu Q, Wu J, Xia X, Ren Q \& Ho PCP 2006 Expression modification of uncoupling proteins and MnSOD in retinal endothelial cells and pericytes induced by high glucose: the role of reactive oxygen species in diabetic retinopathy. Experimental Eye Research 83 807-816. (https://doi.org/10.1016/j.exer.2006.03.024)

Dumollard R, Marangos P, Fitzharris G, Swann K, Duchen M \& Carroll J 2004 Sperm-triggered [Ca2+] oscillations and $\mathrm{Ca} 2+$ homeostasis in the mouse egg have an absolute requirement for mitochondrial ATP production. Development 131 3057-3067. (https://doi.org/10.1242/ dev.01181)

El Hajj N \& Haaf T 2013 Epigenetic disturbances in in vitro cultured gametes and embryos: implications for human assisted reproduction. Fertility and Sterility 99 632-641. (https://doi.org/10.1016/j.fertnstert.2012.12.044)

Fleming TP, Watkins AJ, Velazquez MA, Mathers JC, Prentice AM, Stephenson J, Barker M, Saffery R, Yajnik CS, Eckert JJ et al. 2018 Origins of lifetime health around the time of conception : causes and consequences. Lancet 391 1842-1852. (https://doi.org/10.1016/S01406736(18)30312-X)

Frank LA, Sutton-mcdowall ML, Gilchrist RB \& Thompson JG 2014 The effect of peri-conception hyperglycaemia and the involvement of the hexosamine biosynthesis pathway in mediating oocyte and embryo developmental competence. Molecular Reproduction and Development 81 391-408. (https://doi.org/10.1002/mrd.22299)

Furnus CC, de Matos DG, Martinez A \& Matkovic M 1997 Effect of glucose on embryo quality and post-thaw viability of in-vitro-produced bovine embryos. Theriogenology 47 481-490. (https://doi.org/10.1016/ s0093-691x(97)00006-x)

Galli C, Colleoni S, Duchi R, Lagutina I \& Lazzari G 2007 Developmental competence of equine oocytes and embryos obtained by in vitro procedures ranging from in vitro maturation and ICSI to embryo culture, cryopreservation and somatic cell nuclear transfer. Animal Reproduction Science 98 39-55. (https://doi.org/10.1016/j. anireprosci.2006.10.011)

Guerif F, McKeegan P, Leese HJ \& Sturmey RG 2013 A simple approach for COnsumption and RElease (CORE) analysis of metabolic activity in single mammalian embryos. PLOS ONE 8 e67834. (https://doi. org/10.1371/journal.pone.0067834)

Hashimoto S, Minami N, Takakura R, Yamada M, Imai H \& Kashima N 2000 Low oxygen tension during in vitro maturation is beneficial for supporting the subsequent development of bovine cumulusoocyte complexes. Molecular Reproduction and Development $\mathbf{5 7}$ 353-360. (https://doi.org/10.1002/1098-2795(200012)57:4<353::AIDMRD7>3.0.CO;2-R)

Hendriks WK, Paris DBBP, Colleoni S, Galli C, Colenbrander B \& Stout TAE 2019 Mitochondrial DNA replication is initiated at blastocyst formation in equine embryos. Reproduction, Fertility and Development 31 570-578. (https://doi.org/ 10.1071/RD17387)

Hinrichs K \& DiGiorgio LM 1991 Embryonic development after intrafollicular transfer of horse oocytes. Journal of Reproduction and Fertility. Supplement 44 369-374.

Hinrichs K, Choi YH, Love LB, Varner DD, Love CC \& Walckenaer BE 2005 Chromatin configuration within the germinal vesicle of horse oocytes: changes post mortem and relationship to meiotic and developmental competence. Biology of Reproduction 72 1142-1150. (https://doi. org/10.1095/biolreprod.104.036012)

Hinrichs K, Choi YH, Walckenaer BE, Varner DD \& Hartman DL 2007 In vitro-produced equine embryos: production of foals after transfer, assessment by differential staining and effect of medium calcium 
concentrations during culture. Theriogenology 68 521-529. (https://doi. org/10.1016/j.theriogenology.2007.04.046)

Hinrichs K, Choi YH, Norris JD, Love LB \& Bedford-guaus SJ 2010 Use of intracytoplasmic sperm injection and in vitro culture to the blastocyst stage for clinical production of foals from mares post mortem. Animal Reproduction Science 121 239-240. (https://doi.org/10.1016/j.anireprosci.2010.04.046)

Hinrichs K, Choi YH, Love CC \& Spacek S 2014 Use of in vitro maturation of oocytes, intracytoplasmic sperm injection and in vitro culture to the blastocyst stage in a commercial equine assisted reproduction program. Journal of Equine Veterinary Science 34 176. (https://doi.org/10.1016/j. jevs.2013.10.129)

Hollis AR, Boston RC \& Corley KTT 2007 Blood glucose in horses with acute abdominal disease. Journal of Veterinary Internal Medicine $\mathbf{2 1}$ 1099-1103. (https://doi.org/10.1892/0891-6640(2007)21 [1099:bgihwa ]2.0.co;2)

Jacobson CC, Choi YH, Hayden SS \& Hinrichs K 2010 Recovery of mare oocytes on a fixed biweekly schedule, and resulting blastocyst formation after intracytoplasmic sperm injection. Theriogenology 73 1116-1126. (https://doi.org/10.1016/j.theriogenology.2010.01.013)

Koziel A, Sobieraj I \& Jarmuszkiewicz W 2015 Increased activity of mitochondrial uncoupling protein 2 improves stress resistance in cultured endothelial cells exposed in vitro to high glucose levels. American Journal of Physiology: Heart and Circulatory Physiology 309 H147-H156. (https://doi.org/10.1152/ajpheart.00759.2014)

Leese HJ, Guerif F, Allgar V, Brison DR, Lundin K \& Sturmey RG 2016 Biological optimization, the goldilocks principle, and how much is lagom in the preimplantation embryo. Molecular Reproduction and Development 83 748-754. (https://doi.org/10.1002/mrd.22684)

Lewis NL, Hinrichs K, Schnauffer K, Morganti M \& McG. Argo C 2016 Effect of oocyte source and transport time on rates of equine oocyte maturation and cleavage after fertilisation by ICSI, with a note on the validation of equine embryo morphological classification. Clinical Theriogenology 8 29-43.

Lewis N, Schnauffer K, Hinrichs K, Morganti M, Troup S \& Argo C 2019 Morphokinetics of early equine embryo development in vitro using timelapse imaging, and use in selecting blastocysts for transfer. Reproduction, Fertility, and Development 31 1851-1861. (https://doi.org/10.1071/ RD19225)

Lewis N, Hinrichs K, Leese HJ, Argo CM, Brison DR \& Sturmey R 2020 Energy metabolism of the equine cumulus oocyte complex during in vitro maturation. Scientific Reports 10 3493. (https://doi.org/10.1038/ s41598-020-60624-z)

Morgan R, Keen J \& Mcgowan C 2015 Equine metabolic syndrome. Veterinary Record 177 173-179. (https://doi.org/10.1136/vr.103226)

Muller B, Lewis N, Adeniyi T, Leese HJ, Brison DR \& Sturmey RG 2019 Application of extracellular flux analysis for determining mitochondrial function in mammalian oocytes and early embryos. Scientific Reports 9 16778. (https://doi.org/10.1038/s41598-019-53066-9)

Palmeira CM, Rolo AP, Berthiaume J, Bjork JA \& Wallace KB 2007 Hyperglycemia decreases mitochondrial function: the regulatory role of mitochondrial biogenesis. Toxicology and Applied Pharmacology 225 214-220. (https://doi.org/10.1016/j.taap.2007.07.015)

Ratchford AM, Esguerra CR \& Moley KH 2008 Decreased oocyte-granulosa cell gap junction communication and connexin expression in a Type 1 diabetic mouse model. Molecular Endocrinology 22 2643-2654. (https:// doi.org/10.1210/me.2007-0495)

Rolo AP \& Palmeira CM 2006 Diabetes and mitochondrial function: role of hyperglycemia and oxidative stress. Toxicology and Applied Pharmacology 212 167-178. (https://doi.org/10.1016/j.taap.2006.01.003)

Roseboom TJ 2018 Developmental plasticity and its relevance to assisted human reproduction. Human Reproduction 33 546-552. (https://doi. org/10.1093/humrep/dey034)

Roser JF \& Meyers-Brown G 2012 Superovulation in the mare: a work in progress. Journal of Equine Veterinary Science 32 376-386. (https://doi. org/10.1016/j.jevs.2012.05.055)
Salgado RM, Brom-de-Luna JG, Resende HL, Canesin HS \& Hinrichs K 2018 Lower blastocyst quality after conventional vs. Piezo ICSI in the horse reflects delayed sperm component remodeling and oocyte activation. Journal of Assisted Reproduction and Genetics 35 825-840. (https://doi.org/10.1007/s10815-018-1174-9)

Schmittgen TD \& Livak KJ 2008 Analyzing real-time PCR data by the comparative CT method. Nature Protocols 3 1101-1108. (https://doi. org/10.1038/nprot.2008.73)

Seshagiri PB \& Bavister BD 1989 Glucose inhibits of hamster 8-cell embryos in vitro. Biology of Reproduction 40 599-606. (https://doi. org/10.1095/biolreprod40.3.599)

Smits K \& Govaere J 2010 Birth of the first ICSI foal in the Benelux. Vlaams Diergeneeskundig Tijdschrift 12 134-138.

Spravchikov N, Sizyakov G, Gartsbein M, Accili D, Tennenbaum T \& Wertheimer E 2001 Glucose effects on skin keratinocytes : implications for diabetes skin complications. Diabetes 50 1627-1635. (https://doi. org/10.2337/diabetes.50.7.1627)

Sturmey RG \& Leese HJ 2003 Energy metabolism in pig oocytes and early embryos. Reproduction 126 197-204. (https://doi.org/10.1530/ rep.0.1260197)

Sutton ML, Cetica PD, Beconi MT, Kind KL, Gilchrist RB \& Thompson JG 2003 Influence of oocyte-secreted factors and culture duration on the metabolic activity of bovine cumulus cell complexes. Reproduction $\mathbf{1 2 6}$ 27-34. (https://doi.org/10.1530/rep.0.1260027)

Sutton-McDowall ML, Gilchrist RB \& Thompson JG 2010 The pivotal role of glucose metabolism in determining oocyte developmental competence. Reproduction 139 685-695. (https://doi.org/10.1530/REP-09-0345)

Thompson JG, Simpson AC, Pugh PA \& Tervit HR 1992 Requirement for glucose during in vitro culture of sheep preimplantation embryos. Molecular Reproduction and Development 31 253-257. (https://doi. org/10.1002/mrd.1080310405)

Valenzuela OA, Couturier-Tarrade A, Choi YH, Aubrière MC, Ritthaler I, Chavatte-Palmer P \& Hinrichs K 2018 Impact of equine assisted reproductive technologies (standard embryo transfer or intracytoplasmic sperm injection (ICSI) with in vitro culture and embryo transfer) on placenta and foal morphometry and placental gene expression. Reproduction, Fertility, and Development 30 371-379. (https://doi. org/10.1071/RD16536)

Walter J, Huwiler F, Fortes C, Grossmann J, Roschitzki B, Hu J, Naegeli H, Laczko E \& Bleul U 2019 Analysis of the equine 'cumulome' reveals major metabolic aberrations after maturation in vitro. BMC Genomics 20 588. (https://doi.org/10.1186/s12864-019-5836-5)

Wang Q, Frolova AI, Purcell S, Adastra K, Schoeller E, Chi MM \& Moley KH 2010 Mitochondrial dysfunction and apoptosis in cumulus cells of Type I diabetic mice. PLOS ONE 5 1-11.

Wang Q, Chi MM \& Moley KH 2012 Live imaging reveals the link between decreased glucose uptake in ovarian cumulus cells and impaired oocyte quality in female diabetic mice. Endocrinology 153 1984-1989. (https:// doi.org/10.1210/en.2011-1815)

Watkins AJ, Wilkins A, Cunningham C, Perry VH, Seet MJ, Osmond C, Eckert JJ, Torrens C, Cagampang FRA, Cleal J et al. 2008 Low protein diet fed exclusively during mouse oocyte maturation leads to behavioural and cardiovascular abnormalities in offspring. Journal of Physiology $\mathbf{5 8 6}$ 2231-2244. (https://doi.org/10.1113/jphysiol.2007.149229)

Zhang JJ, Boyle MS, Allen WR \& Galli C 1989 Recent studies on in vivo fertilisation of in vitro matured horse oocytes. Equine Veterinary Journal 21 101-104. (https://doi.org/10.1111/j.2042-3306.1989.tb04691.x)

Received 21 January 2020

First decision 14 February 2020

Revised manuscript received 20 April 2020

Accepted 15 May 2020 